\title{
RANCANG BANGUN SISTEM PEMANTAUAN INFUS BERBASIS ANDROID
}

\author{
Anton Yudhana*), Marta Dwi Darma Putra*) \\ Program Studi Teknik Elektro Universitas Ahmad Dahlan Yogyakarta \\ Jln. Prof.Dr. Supomo Yogyakarta. Tlp. 0274-379418, Fax. 0274-381523 \\ ${ }^{*}$ E-mail: eyudhana@ee.uad.ac.id,dwidarma26@gmail.com
}

\begin{abstract}
Abstrak
Perkembangan dibidang elektronika sangat pesat. Salah satu tugas perawat adalah memantau tetesan infus. Proses pemantauan infus harus dilakukan dengan benar. Saat ini pemantauan infus masih dilakukan secara manual yaitu harus memeriksa kondisi infus pada pasien secara langsung. Pada saat infus habis, perawat memiliki keterbatasan waktu untuk menuju ruang pasien, yang dapat menyebabkan pasien terlambat ditanggulangi. Pada penelitian ini dilakukan perancangan bangun sistem pemantauan infus berbasis android. Alat ini menggunakan photodiode untuk mendeteksi adanya tetesan dan tidak adanya tetesan. Komunikasi antara hardware dan smartphone android menggunakan modul Bluetooth HC-06. Transmitter pada arduino akan mengirimkan data ke smartphone android. Informasi kondisi tetesan infus akan ditampilkan pada app android dan dikonversi menjadi sisa cairan infus pada app android. Apabila sisa cairan infus sama dengan $50 \mathrm{~mL}$, maka ada pemberitahuan pada smartphone android. Berdasarkan hasil simulasi yang telah dilakukan diperoleh kesimpulan bahwa alat dapat mendeteksi pada kecepatan laju tetesan infus 5 tetes/menit, 10 tetes/menit, 20 tetes/menit, 50 tetes/menit, dan ketika klem pada infus dibuka secara total. Rata - rata error sebesar 0.56 $\%$. Simulasi pengiriman data pada Bluetooth HC-06 dilakukan pada gedung yang sama dan didapatkan bahwa Bluetooth HC-06 dapat berkomunikasi dengan baik pada jarak jangkauan $\leq 10 \mathrm{~m}$.
\end{abstract}

Kata kunci : Infus, Photodiode, Android, Arduino.

\begin{abstract}
Abstrack
The development in the field of electronics is very rapid. One of nurse's duties is to monitor drip drops. The infusion monitoring process should be done correctly. Currently infusion monitoring is still done manually by checking the condition in patient directly. When the infusion is exhausted, and nurse has limited time to reach the patient's room, it may cause late response. In this research, we design of infusion monitoring system based on android. This tool uses a photodiode sensor to detect droplets and the absence of droplets. Communication between hardware and android smartphone using Bluetooth HC-06 module. Transmitter on arduino will send data to android smartphone. The infusion droplet information will be displayed on the android app and converted to the rest of the infusion fluid in the android app. If the remaining intravenous fluid is equal to $50 \mathrm{~mL}$, there is a notice on the android smartphone. Based on the simulation results, the tool can detect at the rate of infusion rate of 5 drops / minute, 10 drops / minute, 20 drops / minute, 50 drops / minute, and when the clamp on the infusion is completely opened. The average error is $0.56 \%$. The data transmission simulation on Bluetooth HC-06 is done in the same building and found that Bluetooth HC-06 can communicate well at $\leq 10 \mathrm{~m}$ range.
\end{abstract}

Kata kunci : Infus, Photodiode, Android, Arduino.

\section{Pendahuluan}

Perkembangan dibidang elektronika terutama dalam bidang mikrokontroller dan juga android sangatlah pesat. Arduino merupakan salah satu papan yang berisi mikrokontroller. Arduino ini merupakan mikrokontroller serbaguna yang mudah untuk diprogram [1-2]. Saat ini juga sedang maraknya penggunaan smartphone android. Android merupakan nama system operasi yang bersifat "Open Source". Android dapat terhubung dengan peralatan elektronika untuk mengendalikan ataupun menerima informasi dari peralatan elektronika [3].

Perkembangan elektronika di bidang kedokteran juga berkembang [4-6], dan dapat membantu pekerjaan seorang perawat untuk memantau kondisi pasiennya. Salah satunya adalah dalam pemantauan tetesan infus. Pemasangan infus merupakan tindakan yang dilakukan pada pasien dengan cara memasukkan cairan intra vena dengan bantuan infus set dengan tujuan memenuhi kebutuhan cairan dan elektrolit [7]. Saat ini pemantauan infus masih dilakukan 
secara manual yaitu perawat harus memeriksa kondisi infus pada pasien secara langsung. Pada saat infus habis, perawat memiliki keterbatasan waktu untuk menuju ruang pasien yang dapat menyebabkan pasien terlambat ditanggulangi Keterlambatan dalam penggantian botol infus dapat mengakibatkan masuknya udara yang turut serta masuk ke dalam sistem sirkulasi [8].

Pada penelitian ini dilakukan perancangan bangun sistem pemantauan infus berbasis android. Alat ini menggunakan papan arduino dan sensor photodiode dan app android yang dirancang menggunakan MIT App Inventor [9-10]. MIT App Inventor adalah alat untuk membuat aplikasi android, didasarkan pada pemrograman blok visual.

\section{Metode}

\subsubsection{Perancangan Sistem}

Perancangan sistem disajikan dalam bentuk diagram blok. Diagram blok desain dan sistem kerja alat dapat dilihat pada Gambar 1 .

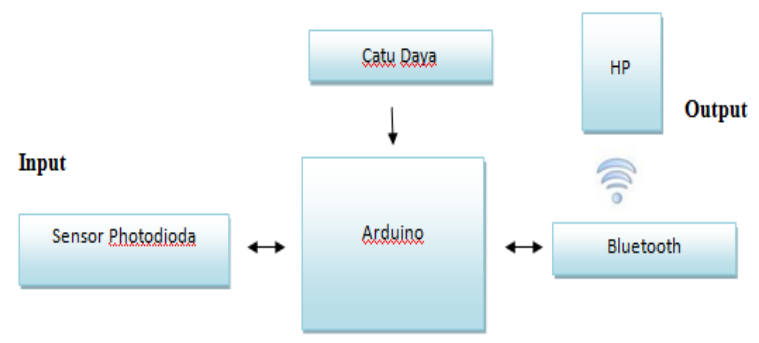

Gambar 1. Blok Diagram Proses Kerja Alat Secara Umum

\subsection{Perancangan perangkat keras}

Perancangan perangkat keras terdiri dari sistem kontrol sistem arduino yang bertugas sebagai sensorcontroller dan melakukan pengolahan data. Seluruh rangkaian sistem dapat dilihat pada Gambar 2.

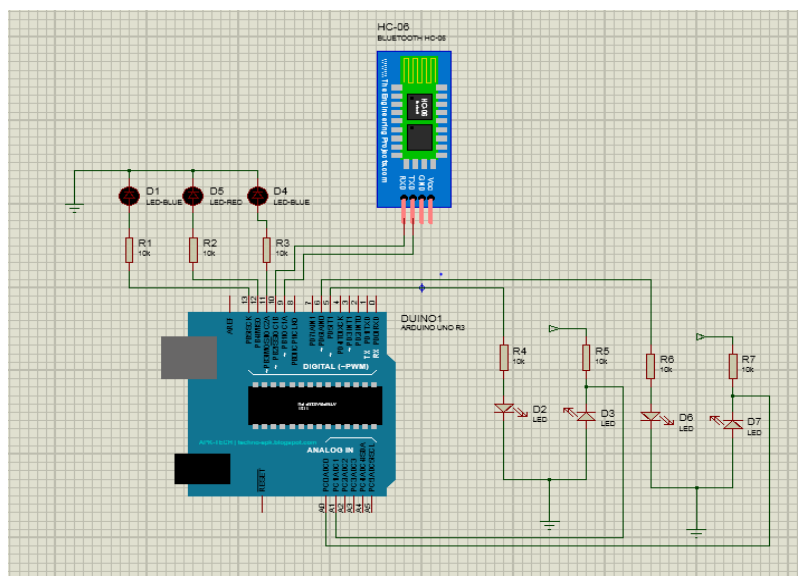

Gambar 2. Rangkaian Sistem mikrokontroler Arduino Uno

\subsection{Perancangan Hardware}

Perancangan perangkat lunak menggunakan perangkat lunak arduino yang kemudian diunduh di arduino uno. Diagram alir dapat dilihatb pada gambar 3 .

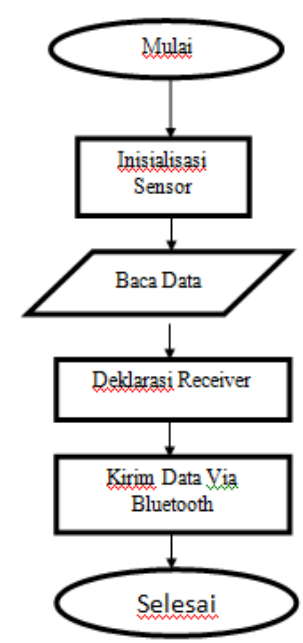

Gambar 3. Diagram alir

\subsection{Desain Perangkat Android}

Desain perangkat android ini didesain sebagai receiver. Perancangan perangkat android menggunakan MIT App Inventor.

\section{Hasil Dan Pembahasan \\ 3.1. Pengujian Perangkat Keras}

Pengujian Perangkat Keras ini dilakukan dengan melakukan serangkaian pengujian pada yaitu sensor photodiode dan modul Bluetooth yang telah dirangkai dengan papan arduino.

\subsubsection{Pengujian Sensor Photodioda}

Pengujian sensor photodioda dilakukan untuk mengetahui respon yang diberikan oleh sensor.. Maka didapat hasil seperi pada Tabel 1 .

Tabel 1.Keterangan Vin dan Vout pada sensor photodiode

\begin{tabular}{cccc}
\hline Sensor & $\begin{array}{c}\text { Tegangan } \\
\text { Input }\end{array}$ & $\begin{array}{c}\text { Output } \\
\text { Tegangan }\end{array}$ & Keterangan \\
\hline Sensor I & $5 \mathrm{~V}$ & $\begin{array}{c}1.42 \mathrm{DCV} \\
4.88 \mathrm{DCV}\end{array}$ & $\begin{array}{c}\text { Terkena cahaya } \\
\text { Tidak terkena cahaya }\end{array}$ \\
\multirow{2}{*}{ Sensor II } & $5 \mathrm{~V}$ & $\begin{array}{l}1.66 \mathrm{DCV} \\
4.88 \mathrm{DCV}\end{array}$ & $\begin{array}{c}\text { Terkena cahaya } \\
\text { Tidak terkena cahaya }\end{array}$ \\
\hline
\end{tabular}

Dari pengujian tersebut dapat diketahui output sensor photodioda akan bernilai low jika terkena cahaya , sedangkan sensor akan bernilai high jika tidak terkena cahaya. 


\subsubsection{Pengujian Modul Bluetooth}

Pada pengujian koneksi bluetooth ke android merupakan komunikasi antara hardware dengan smartphone android dengan menghubungkan modul Bluetooth HC-06 dengan arduino uno Pengujian koneksi bluetooth ditunjukan pada Tabel 2.

\section{Tabel 2. Pengujian koneksi Bluetooth}

\begin{tabular}{rcc}
\hline No & $\begin{array}{c}\text { Jarak antara sistem } \\
\text { Bluetooth }\end{array}$ & Keterangan \\
\hline 1 & 1 Meter & Lancar menerima \\
2 & 5 Meter & Lancar menerima \\
3 & 6 Meter & Lancar menerima \\
4 & 7 Meter & Lancar menerima \\
5 & 8 Meter & Lancar menerima \\
6 & 9 Meter & Lancar menerima \\
7 & 10 Meter & Lancar menerima \\
8 & 11 Meter & Tidak lancar menerima \\
9 & 12 Meter & Tidak Menerima \\
10 & 13 Meter & Tidak Menerima \\
11 & 14 Meter & Tidak Menerima \\
12 & 15 Meter & Tidak Menerima \\
\hline
\end{tabular}

Pengujian sistem koneksi antara bluetooth HC-06 dengan bluetooth yang ada di dalam sistem smartphone android. Jarak yang sangat efektif adalah 1 meter sampai 10 meter untuk menstabilkan hasil ukur pada sensor yang dikoneksikan pada android.

\subsection{Pengujian Aplikasi pada Smartphone Android}

Pengujian sistem ini dilakukan dengan cara meng instalasi aplikasi yang telah dibuat dengan menggunakan MIT App Inventor. Aplikasi diberi nama "Infus". Tampilan untuk membuka aplikasi di tunjukan pada Gambar 5.

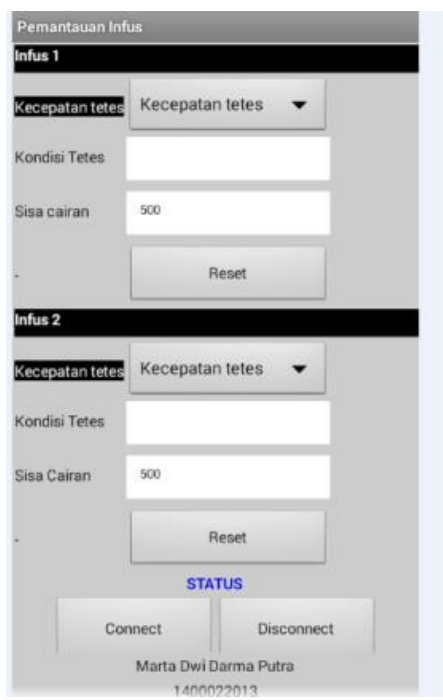

Gambar 5. Aplikasi pemantauan pada android

Aplikasi android pada saat sisa cairan infus $=50.095 \mathrm{~mL}$ dapat memberikan pemberitahuan kepada perawat berupa dialog box dengan notifikasi teks "Infus 1 akan segera habis. Segera lakukan penggantian pada infus 1". Disertai juga dengan notifikasi berupa nada suara yang berbunyi "Infus 1 akan habis"

\subsection{Hasil dan Pengujian Data}

Untuk pengujian alat diaplikasikan secara langsung menggunakan infus set. Pengujian pada infus dapat dilihat pada Gambar 6.

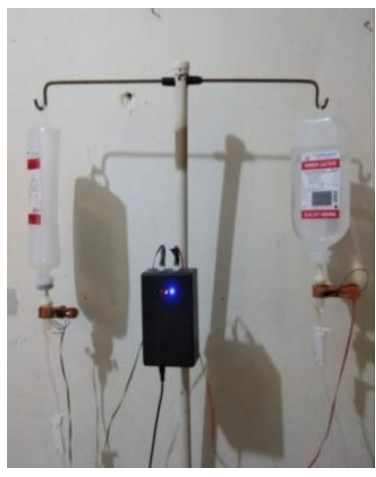

Gambar 6. Gambaran secara keseluruhan

\subsubsection{Pengujian sensor pendeteksi tetesan}

Pada alat ini terdapat 2 (dua) sensor pendeteksi tetesan yaitu pendeteksi tetesan pada infus I dan pendeteksi tetesan pada infus II. Maka dari itu dilakukan pengujian pada infus I dan infus II.

1. Pengujian sensor pendeteksi pada infus I

Dalam pengujian sensor pendeteksi tetesan pada infus

1. Hasil pengujian dapat dilihat dilihat pada Tabel 3.

Tabel 3. Hasil Pengujian Sensor Pendeteksi Tetesan Infus I

\begin{tabular}{cccc}
\hline No & Kondisi Tetesan & $\begin{array}{c}\text { Kondisi LED } \\
\text { Indikator }\end{array}$ & $\begin{array}{c}\text { Vout } \\
\text { Sensor }\end{array}$ \\
\hline 1 & Menetes & Kedip & $1.42 \mathrm{DCV}$ \\
2 & Tidak Menetes & Padam & $4.88 \mathrm{DCV}$ \\
\hline
\end{tabular}

2. Pendeteksi tetesan pada infus II

Dari pengujian sensor pendeteksi tetesan pada infus II. Hasil pengujian dapat dilihat dilihat pada Tabel 4.

Tabel 4. Hasil Pengujian Sensor Pendeteksi Tetesan Infus II

\begin{tabular}{cccc}
\hline No & Kondisi Tetesan & $\begin{array}{c}\text { Kondisi LED } \\
\text { Indikator }\end{array}$ & $\begin{array}{c}\text { Vout } \\
\text { Sensor }\end{array}$ \\
\hline 1 & Menetes & Kedip & $1.66 \mathrm{DCV}$ \\
2 & Tidak Menetes & Padam & $4.88 \mathrm{DCV}$ \\
\hline
\end{tabular}

\subsubsection{Pengujian Pengamatan Sisa Cairan Infus}

Tampilan sisa cairan infus akan berkurang setiap tetesnya. Jika $1 \mathrm{~mL}=15$ tetes makro maka 1 tetes $=0.067 \mathrm{~mL}$, jadi setiap tetesnya akan berkurang $0.067 \mathrm{~mL}$. 
Dari pengujian pengamatan sisa cairan infus pada infus I dilakukan dengan menguji pembacaan pengamatan sisa cairan infus pada kecepatan 5 tetes/menit, 10 tetes/menit, 20 tetes/menit, 50 tetes/menit dan ketika klem pada infus dibuka secara total.

\section{a. Pengujian pada kecepatan 5 tetes/menit}

Pada pengujian sisa cairan infus ini dilakukan dengan mengatur klem pada infus dengan kecepatan 5 tetes/menit, Hasil yang didapat dapat dilihat pada Tabel 5.

Tabel 5. Hubungan sisa cairan infus pada kecepatan 5 tetes/menit

\begin{tabular}{ccccc}
\hline No & Waktu $(\mathrm{m})$ & $\begin{array}{c}\text { Sisa Infus pada } \\
\text { aplikasi }(\mathrm{mL})\end{array}$ & $\begin{array}{c}\text { Sisa Infus } \\
\text { pada real } \\
\text { time }(\mathrm{mL})\end{array}$ & Error (\%) \\
\hline 1 & 0 & 500 & 500 & 0 \\
2 & 15 & 494.975 & 495 & 0.0050 \\
3 & 30 & 489.95 & 490 & 0.0102 \\
4 & 45 & 484.925 & 485 & 0.0155 \\
5 & 60 & 479.9 & 480 & 0.0208 \\
6 & 75 & 474.875 & 475 & 0.0263 \\
7 & 90 & 469.85 & 470 & 0.0319 \\
8 & 105 & 464.624 & 465 & 0.0808 \\
9 & 120 & 459.666 & 460 & 0.0726 \\
& \multicolumn{5}{c}{ Rata- rata error (\%) } \\
\hline
\end{tabular}

Pembacaan sisa cairan infus pada aplikasi memiliki hasil yang sama dengan sisa cairan infus yang dihitung secara manual dengan rata - rata error sebesar $0.0292 \%$.

b. Pengujian pada kecepatan 10 tetes/menit

Pada pengujian sisa cairan infus ini dilakukan dengan mengatur klem pada infus dengan kecepatan 10 tetes/menit. Hasil yang didapat dapat dilihat pada Tabel 6.

Tabel 6. Hubungan sisa cairan infus pada kecepatan 10 tetes/menit

\begin{tabular}{ccccc}
\hline No & Waktu $(\mathrm{m})$ & $\begin{array}{c}\text { Volume Infus } \\
\text { pada aplikasi } \\
(\mathrm{mL})\end{array}$ & $\begin{array}{c}\text { Volume Infus } \\
\text { pada real time } \\
(\mathrm{mL})\end{array}$ & Error (\%) \\
\hline 1 & 0 & 500 & 500 & 0.0000 \\
2 & 15 & 489.95 & 490 & 0.0102 \\
3 & 30 & 479.9 & 480 & 0.0208 \\
4 & 45 & 469.85 & 470 & 0.0319 \\
5 & 60 & 459.8 & 460 & 0.0435 \\
6 & 75 & 449.75 & 450 & 0.0556 \\
7 & 90 & 439.7 & 440 & 0.0682 \\
8 & 105 & 429.65 & 430 & 0.0814 \\
9 & 120 & 419.6 & 420 & 0.0952 \\
& \multicolumn{5}{c}{ Rata - rata error $(\%)$} & & 0.0452 \\
\hline
\end{tabular}

Pengambilan data dengan mengatur kecepatan pada infus sebesar 10 tetes/menit. Pembacaan sisa cairan infus pada aplikasi memiliki hasil yang sama dengan sisa cairan infus yang dihitung secara manual dengan rata - rata error sebesar $0.0452 \%$.

c. Pengujian pada kecepatan 20 tetes/menit Pada pengujian sisa cairan infus ini dilakukan dengan mengatur klem pada infus dengan kecepatan 20 tetes/menit. Hasil yang didapat dapat dilihat pada Tabel 7.

Tabel 7. Hubungan sisa cairan infus pada kecepatan 20 tetes/menit

\begin{tabular}{ccccc}
\hline No & Waktu $(\mathrm{m})$ & $\begin{array}{c}\text { Volume Infus } \\
\text { pada aplikasi } \\
(\mathrm{mL})\end{array}$ & $\begin{array}{c}\text { Volume Infus } \\
\text { pada real time } \\
(\mathrm{mL})\end{array}$ & Error $(\%)$ \\
\hline 1 & 0 & 500 & 500 & 0.0000 \\
2 & 30 & 459.8 & 460 & 0.0435 \\
3 & 60 & 419.6 & 420 & 0.0952 \\
4 & 90 & 379.4 & 380 & 0.1579 \\
5 & 120 & 339.2 & 340 & 0.2353 \\
6 & 150 & 299 & 300 & 0.3333 \\
7 & 180 & 258.8 & 260 & 0.4615 \\
8 & 210 & 218.6 & 220 & 0.6364 \\
& \multicolumn{5}{c}{ Rata - rata error (\%) } \\
\hline
\end{tabular}

Pembacaan sisa cairan infus pada aplikasi memiliki hasil yang sama dengan sisa cairan infus yang dihitung secara manual dengan rata - rata error sebesar 0.2454 $\%$.

d. Pengujian pada kecepatan 50 tetes/menit Pada pengujian sisa cairan infus ini dilakukan dengan mengatur klem pada infus dengan kecepatan 50 tetes/menit. Hasil yang didapat dapat dilihat pada Tabel 8.

Tabel 8. Hubungan sisa cairan infus pada kecepatan 50 tetes/menit

\begin{tabular}{ccccc}
\hline No & Waktu $(\mathrm{m})$ & $\begin{array}{c}\text { Volume Infus } \\
\text { pada aplikasi } \\
(\mathrm{mL})\end{array}$ & $\begin{array}{c}\text { Volume Infus } \\
\text { pada real time } \\
(\mathrm{mL})\end{array}$ & Error (\%) \\
\hline 1 & 0 & 500 & 500 & 0.0000 \\
2 & 15 & 449.75 & 450 & 0.0556 \\
3 & 30 & 399.5 & 400 & 0.1250 \\
4 & 45 & 349.25 & 350 & 0.2143 \\
5 & 60 & 299 & 300 & 0.3333 \\
6 & 75 & 248.75 & 250 & 0.5000 \\
7 & 90 & 198.5 & 200 & 0.7500 \\
8 & 105 & 148.25 & 150 & 1.1667 \\
9 & 120 & 98 & 100 & 2.0000 \\
10 & 130 & 64.5 & 66 & 2.2727 \\
& \multicolumn{5}{c}{ Rata - rata error $(\%)$} \\
\end{tabular}

Pembacaan sisa cairan infus pada aplikasi memiliki hasil yang sama dengan sisa cairan infus yang dihitung secara manual dengan rata - rata error sebesar 0.7418 $\%$.

e. Pengujian pada saat klem infus terbuka secara total Pada pengujian sisa cairan infus ini dilakukan dengan dengan mengatur klem pada infus terbuka secara total. Hasil yang didapat dapat dilihat pada Tabel 9. 
Tabel 9. Hubungan sisa cairan infus saat klem infus dibuka secara total

\begin{tabular}{ccccc}
\hline No & Waktu $(\mathrm{m})$ & $\begin{array}{c}\text { Volume Infus } \\
\text { pada aplikasi } \\
(\mathrm{mL})\end{array}$ & $\begin{array}{c}\text { Volume Infus } \\
\text { pada real } \\
\text { time }(\mathrm{mL})\end{array}$ & Error $(\%)$ \\
\hline 1 & 0 & 500 & 500 & 0.0000 \\
2 & 5 & 450.42 & 450 & 0.0933 \\
3 & 10 & 400.84 & 400 & 0.2100 \\
4 & 15 & 351.26 & 350 & 0.3600 \\
5 & 20 & 301.68 & 300 & 0.5600 \\
6 & 25 & 252.1 & 250 & 0.8400 \\
7 & 30 & 202.52 & 200 & 1.2600 \\
8 & 35 & 152.94 & 150 & 1.9600 \\
9 & 40 & 103.36 & 100 & 3.3600 \\
10 & 45 & 53.78 & 50 & 7.5600 \\
& \multicolumn{5}{r}{ Rata - rata error (\%) } \\
\hline
\end{tabular}

Pembacaan sisa cairan infus pada aplikasi memiliki hasil yang sama dengan sisa cairan infus yang dihitung secara manual dengan rata - rata error sebesar $0.5637 \%$.

Dari semua pengujian diatas maka diperoleh tabel rata rata error yang diambil semua hasil simulasi yang telah dilakukan pada kecepatan laju tetesan infus 5 tetes/menit, 10 tetes/menit, 20 tetes/menit, 50 tetes/menit, dan ketika klem pada infus dibuka secara total dapat dilihat pada Tabel 10

Tabel 10. Rata - rata error pada sensor 1

\begin{tabular}{ccc}
\hline No & $\begin{array}{c}\text { Kecepatan laju tetesan infus } \\
\text { (tetes/ menit) }\end{array}$ & $\begin{array}{c}\text { Rata - rata } \\
\text { error (\%) }\end{array}$ \\
\hline 1 & 5 & 0.0292 \\
2 & 10 & 0.0452 \\
3 & 20 & 0.2454 \\
4 & 50 & 0.7418 \\
5 & klem pada infus dibuka & 0.5637 \\
Rata - rata error keseluruhan & 0.32506 \\
\hline
\end{tabular}

\section{Kesimpulan}

Telah berhasil dibuat aplikasi android yang mampu memantau tetesan infus dan sisa cairan infus yang dirancang dengan menggunakan MIT App Inventor. Pada hasil yang telah di dapatkan dalam semua pengujian, rancang bangun system pemantauan infus berbasis android dapat memantau kondisi tetes dan sisa cairan pada infus, dan memberikan notifikasi kepada perawat apabila infus akan habis. Maka dengan seperti ini alat sudah sesuai dengan tujuan penelitian. Berdasarkan hasil pengamatan, perbandingan data antara pemantauan kondisi tetesan dan dan sisa cairan pada infus, didapat kesimpulan bahwa aplikasi android pada saat sisa cairan infus $=50.095 \mathrm{~mL}$ dapat memberikan pemberitahuan kepada perawat berupa dialog box dengan notifikasi yang sesuai, maupun pesan suara.
Berdasarkan simulasi yang telah dilakukan alat dapat mendeteksi tetesan infus pada kecepatan laju tetesan infus 5 tetes/menit, 10 tetes/menit, 20 tetes/menit, 50 tetes/menit, dan ketika klem pada infus dibuka secara total dengan rata - rata error keseluruhan sebesar $0.32506 \%$.

\section{Referensi}

[1]. Kadir,A. 2015. Buku Pintar Pemrograman Arduino .Yogyakarta:MediaKom

[2]. Arboleda, Edwin R., Yna Victoria P. Paulite, and Neil Jerome C. Carandang. "Smart Wheelchair with Dual Control using Touchpad and Android Mobile Device." Indonesian Journal of Electrical Engineering and Informatics (IJEEI) 6.1 (2018): 86-96

[3]. ALFoudery, Adel, Abdulrahman Abdullah Alkandari, and Nayfah Mohsen Almutairi. "Trash Basket Sensor Notification Using Arduino with Android Application." Indonesian Journal of Electrical Engineering and Computer Science 10.1 (2018): 120-128.

[4]. Aziz, Sukma Bahrul, Tengku A. Riza, and Rohmat Tulloh. "Perancangan dan Implementasi Aplikasi Sistem Antrian untuk Pasien pada Dokter Umum Berbasis Android dan SMS Gateway." Jurnal Elektro dan Telekomunikasi Terapan 2.1 (2015).

[5]. Pawar, Pravin Amrut, and Sagar P. Mohammad. "Review of quality of service in the mobile patient monitoring systems." IEEE Region 10 Symposium (TENSYMP), 2017. IEEE, 2017.

[6]. Kurniadi, Dede, M. Mesa Fauzi, and Asri Mulyani. "Aplikasi Simulasi Tes Buta Warna Berbasis Android Menggunakan Metode Ishihara." Jurnal Algoritma 13.1 (2016).

[7]. Ambarwati, F. R dan N. Nasution. 2015. Ketrampilan dasar Praktik Klinik. Yogyakarta: Parana Ilmu

[8]. Potter, P. A dan A. G. Perry. 2006. Buku ajar fundamental keperawatan: konsep, proses, dan praktik. Jakarta: EGC

[9]. Kadir,A. 2017. Pemrograman Arduino \& Android menggunakan App Inventor.Jakarta: PT Elex Media Komputindo

[10]. MIT App Inventor, 2017 http://appinventor.mit.edu/explore/ Diakses pada tanggal 26 Agustus 2017 